\title{
Having children outside a heterosexual relationship - options for persons living with HIV
}

Tristan J Barber ${ }^{1}$, Tuvia Borok ${ }^{2}$, Tara Suchak ${ }^{3}$, Alison Weatherall ${ }^{4}$, Tor Doherty ${ }^{5}$, Natalie Gamble ${ }^{6}$, Robert

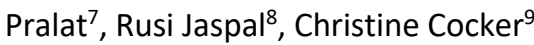

1 Royal Free NHS Foundation Trust, London UK

2 P3 Network

3 Chelsea and Westminster NHS Foundation Trust, London UK

4 CARE Fertility

$5 \quad$ New Family Social

$6 \quad$ NGA Law

7 University of Cambridge, UK

8 De Montfort University, Leicester UK

9 University of East Anglia, UK

Word count: Currently 2217 (doesn't include 'further information' or 'references')

All authors contributed to this paper with Dr Tristan Barber having overarching and final responsibility for collating individual works into the finished article.

The Corresponding Author has the right to grant on behalf of all authors and does grant on behalf of all authors, an exclusive licence (or non exclusive for government employees) on a worldwide basis to the BMJ Publishing Group Ltd to permit this article (if accepted) to be published in STI and any other BMJPGL products and sub-licences such use and exploit all subsidiary rights, as set out in our licence http://group. bmj. com/products/journals/instructions-for-authors/licence-forms. 


\section{Corresponding author:}

Dr Tristan J Barber

Ian Charleson Centre

Royal Free Hospital

Pond Street

London NW3 2QG

t.barber@nhs.net 


\section{Introduction}

This article presents information about the social, legal and medical issues that medical and non-medical practitioners in the UK' should consider in order to signpost options for people living with HIV (PLWH) who are not in a heterosexual relationship and want to become parents. Despite significant medical advances, increased medical awareness amongst HIV practitioners, and the ability to live a full life with HIV, stigma still exists around PLWH wanting to have children. There is a lack of awareness amongst the general public and the non-specialist medical community, about the realities of living with HIV, and the options available to become a parent.

Vertical transmission rates in the UK are very low $(<0.5 \%)$ [1]. Despite this, even amongst PLWH it is evident that stigma surrounding parenting with HIV is real, with almost 50\% of HIV-positive respondents in a European study saying that having HIV would be a barrier to them deciding to have a family [2]. Irrespective of their sexual orientation, HIV-positive parents and prospective parents may bear not only the brunt of an historical HIV stigma, but also the negative discourses that surround lesbian, gay, bisexual or transgendered/gender diverse (LGBT) parenting, despite the legal advances over the past decade.

First steps to breaking down this stigma are to increase public awareness around the realities of living with HIV, and awareness among PLWH that being a parent is an option for them. In 2016 in London, the UNAIDS 90-90-90 target was achieved for the first time. England came close to meeting that target, with $88 \%$ of those living with HIV being diagnosed, $96 \%$ of those on HIV treatment and $97 \%$ of them having an undetectable viral load [3]. Most PLWH taking antiretroviral medication therefore have undetectable levels of HIV in blood, meaning they cannot transmit HIV via sexual fluids [4].

Despite this, parenting is not always routinely discussed with PLWH. A recent study in London HIV clinics found that very few clinicians spoke with HIV-positive gay men about the possibility of having children [5]. Misconceptions about HIV transmission risk and medico-legal issues concerning reproduction may, thus, be rarely addressed. Education is also key to challenging stigma, and supporting the medical profession to better

'The legal content is UK-wide (since it derives from the UK Human Fertilisation and Embryology Act 2008). Other aspects, such as NHS funding for fertility treatment, may vary between UK countries. 
advise HIV-positive patients is critical, as a medical appointment is often the first opportunity that people who are newly diagnosed have to think about future options.

\section{Transmission}

The key to conceiving a child and preventing transmission to an unborn baby in HIV positive parents lies within the evidence behind current understanding of viral load and the risk of HIV transmission.

PrEP (Pre Exposure Prophylaxis) is a new way of preventing HIV transmission. HIV negative people can take a tablet (containing two active drugs, tenofovir and emtricitabine) before they have unprotected sex. Taking PrEP has shown to be incredibly effective at preventing HIV acquisition $[6,7,8]$. PrEP is different to PEP (Post Exposure Prophylaxis). PEP is a medication regimen taken for 28 days after a risk of acquisition of HIV.

When a person first becomes HIV positive they will have a very high viral load. This makes the chance of transmitting the virus very high. When a patient commences therapy the viral load falls rapidly, the aim being becoming undetectable in plasma ( $<50$ copies $/ \mathrm{ml}$ ). Once someone is undetectable their HIV is untransmittable $\left(\mathrm{U}=\mathrm{U}^{\mathrm{ii}}\right)[4,9]$.

Both PEP and PrEP were considered useful tools to reducing HIV transmission around the time of conception in sero-discordant heterosexual couples. However since the adoption of $\mathrm{U}=\mathrm{U}$, their use is not recommended. So long as the HIV positive parent is undetectable PEP and PrEP are not recommended to safeguard the negative parent.

This has transformed the options PLWH have regarding parenting, although the ethical and legal frameworks for some options lag behind the evidence. For example, serodifferent heterosexual couples where the male partner is HIV infected are no longer advised to undergo sperm washing if the male partner satisfies $U=U$ criteria, but when surrogacy or donor insemination is considered extra barriers remain in place for those affected by HIV. Some USA clinics use the 'Bedford Programme' [10] to allow HIV positive men to pursue conception via these routes but regulatory frameworks in the UK do not support this approach.

\footnotetext{
i"https://www.preventionaccess.org/consensus; accessed 26 ${ }^{\text {th }}$ April 2018
} 


\section{Women and Fertility}

Women living with HIV have been found to have reduced fertility which may be due to the fact that an increase in tubal factors is seen. Men living with HIV, especially if infection occurred around puberty, may have a reduced sperm count [11]. Couples are therefore advised to seek fertility investigations if they have tried to conceive for 6 months without success, or are known to have had previous pelvic infections.

\section{What's possible?}

There are a number of possibilities for PLWH to have biogenetically related children. Parental gender, relationship status and financial resources will impact on the available options.

\section{Single Women}

For single women, many UK fertility clinics offer treatment with donor sperm. The success rates for intrauterine insemination (IUI) are around $10 \%$ so many women opt to have in vitro fertilisation (IVF) which has better success rates, but is more expensive, particularly if paying privately. Local Clinical Commissioning Groups (CCGs) will have specific policies on what funding might be available through the NHS. For example, some CCGs will not fund fertility treatment for single women.

\section{Single Men}

The options for single men are not as straightforward. Although many UK clinics can provide access to treatment using donor eggs, a parental order (which reassigns parentage after surrogacy) can only obtained by two people, who have to be either married, in a civil partnership or living as partners. The law is currently being changed to allow single parents to apply for parental orders, with the changes (at the time of writing) due to come into force in late 2018 or during the course of 2019. 
In the meantime there are other ways of obtaining parental responsibility for single parents and surrogacy is, in reality, an option for both single men and women.

Single people can also choose a co-parenting route. For example, a woman (the "birth mother") and man with whom she is not in a relationship can choose to have a child together - they do not need to be in a relationship but both people would be the legal parents of a child with all the responsibilities that that brings. Having a legal document that sets out parenting agreements and arrangements prior to a child's birth is a useful tool in these circumstances, as it offers protection to both parties. Additional infectious disease screening (for sexually transmitted infections and other blood born viruses such as hepatitis B and C) might also be necessary to remove the risk of infection through using a male co-parenting partner's sperm that the parent carrying the child wouldn't otherwise be exposed to. Provided $U=U$ criteria are met then there is, of course, no risk of HIV exposure to the uninfected parent or to any conceived child.

A single man, or same sex male couples, can commission a surrogate host to carry their baby. The law in this area is complex and surrogacy agreements are not enforceable in the UK. Commissioning individuals or couples use donated eggs, which are inseminated with the sperm of either partner to create the embryos that are then transferred to a surrogate host. It is not possible to use donor sperm in this scenario because one person must be genetically related to a child before a parental order can be issued [12]. In the UK, fertility clinics can only legally use HIV negative sperm with a surrogate, so some parents go overseas for treatment instead, usually to the USA where there are established fertility treatment and surrogacy programmes for intended parents living with HIV. Parents will need to apply for a UK parental order after a child is born to secure legal parentage.

Couples

Same sex female couples can access treatment using donor sperm, but if they opt for IVF rather than IUI they can choose to explore one partner donating eggs to the other and vice versa. Despite this, for a woman living with HIV it is not possible, due to HFEA regulation, to provide eggs to her partner (or any other recipient) at a 
fertility clinic in the UK. There is a legal obligation to follow medical advice to minimise any risk of transmission to an unborn baby, and a fertility clinic will also need to consider the welfare of a child before treatment. If a UK clinic is used, both can be registered on the birth certificate as a child's legal parents if they sign the correct forms at the clinic before conception and the donor's rights are extinguished. If they conceive by artificial insemination elsewhere, then both can be recorded on the birth certificate if they were married or in a civil partnership at the time of conception [13].

Whilst full exploration of issues for those who identify as transgender or transitioning is outside the scope of this article, it is worth nothing that for these individuals options vary depending on whether they stored gametes before transition or not. Anyone storing gametes should have 'at the time of donation' infection screening. Unless this confirms HIV negative status, it is not possible to transfer embryos to a surrogate host or a co-parent in the UK in the future.

\section{Funding}

NHS funding for non-heterosexual parenting varies but is worth investigating in cases of known infertility. If NHS funding or private financial resources are not available some women egg share, giving them the chance to help others while receiving benefit in kind to fund their own treatment. Some clinics also offer men the option to sperm share. PLWH are not permitted to participate in egg or sperm sharing under UK regulations so these options are not available to them.

\section{Options for fostering and adoption}

Being HIV positive would not on its own limit an adoption or fostering assessment being undertaken or be a barrier to adopt or foster a child. Applicants who are single or in a same-sex relationships are encouraged to apply. However, no one has the 'right' to foster or adopt a child. Agencies assess applicants to ensure that all adopters and foster carers have the necessary qualities and experiences to care for children who have had 
traumatic and abusive experiences. The challenges that HIV applicants have handled successfully in their own lives may well be regarded as assets in the assessment process. The assessment includes health (including mental health) inquiries to ensure that applicants have a reasonable expectation of continuing good health and, in the case of adoption, the ability to support a child until adulthood. Although legally an HIV status does not need to be disclosed, in practice it is not ever advisable to keep it a secret, especially as the assessment process is built entirely on openness. A letter from an HIV specialist can provide the assessing local authority, the adoption medical adviser and the adoption panel with evidence about the health of the applicant(s) with HIV, including commenting on life expectancy, and this can also include information about the impossibility of HIV transmission from domestic contacts. The agency should only share an applicant's HIV status on a 'needto-know' basis, with informed consent. This is an issue that should be discussed with an assessing social worker.

\section{Supporting PLWH parenting}

Some of the policy and practice in relation to positive parenting appears to be out of step with the current scientific evidence as we have seen. In addition, the social, psychological and emotional implications of parenting among LGBT people living with HIV can be considerable, as parenting itself represents a significant change to identity. Becoming a parent can change one's relationship with one's partner, family and social environment, as well as the 'identity hierarchy' in that parenthood can become more important than other dimensions, such as one's occupational identity [14]. As with other stigmatised identities there is a high prevalence of poor mental health and childhood psychological adversity in HIV patients [15,16]. Strategies and interventions for promoting and enhancing social, psychological and emotional wellbeing are essential. Any potential psychosocial challenges of positive parenting could be addressed through counselling, mental health care and mutual social support from other positive parents. The recently updated BHIVA Standards of Care [17] may be referred to for more detail about expected levels of emotional wellbeing and support. 


\section{Summary}

Many options are available for PLWH to considering parenting. Asking about this as part of routine care helps support destigmatising messages about normal life expectancy with HIV infection. Further work needs to be done to educate medical professionals and the wider public about the $\mathrm{U}=\mathrm{U}$ message, and positive experiences of LGBT parenting. National guidelines and standards for HIV care should include resources to support PLWH choosing to parent, ensuring that parenting desire is enquired about and recorded. Ethical frameworks to support biological parenting for PLWH should be developed so that it is integrated into 'business as usual' service delivery.

\section{Further information}

More information is available at a newly launched resource hub at www.hivandfamily.com, spearheaded by The P3 Network (www.thep3network.com) as part of its 'Positive Parenting' campaign, with the key message that 'HIV doesn't define a parent's power to love'. The campaign and resource hub was backed by organisations including the British HIV Association, Children's HIV Association, Terrence Higgins Trust and clinicians at the Royal Free and Chelsea and Westminster NHS Foundation Trusts.

\section{References}

1 Peters $\mathrm{H}$, Francis $\mathrm{K}$, Sconza $\mathrm{R}$ et al. UK mother-to-child transmission rates continue to decline: 2012-2014. Clin Infect Dis 2016; 64: 527-528.

2 http://www.hivisjustapartofme.eu/CMSUploads/HIV-diagnosis-infographic.pdf; accessed 14th April 2018

3 Towards elimination of HIV transmission, AIDS and HIV-related deaths in the UK. Published November 2017 PHE publications gateway number: 2017572 
https://assets.publishing.service.gov.uk/government/uploads/system/uploads/attachment data/file/ 675809/Towards elimination of HIV transmission AIDS and HIV related deaths in the UK.pdf

4 Rodger AJ et al for the PARTNER study group. Sexual activity without condoms and risk of HIV transmission in serodifferent couples when the HIV-positive partner is using suppressive antiretroviral therapy. JAMA, 2016;316(2):1-11. DOI: 10.1001/jama.2016.5148 (12 July 2016).

5 R Pralat, M Johnson, S Franklin, J Anderson, M Boffito, T Barber, F Burns. Should healthcare practitioners discuss parenthood possibilities with HIV-positive MSM? Preliminary findings from the MAIL Study. Poster presentation, BHIVA 2017, Liverpool UK.

6 Grant RM et al. Preexposure chemoprophylaxis for HIV prevention in men who have sex with men. New Engl Jour Med 363(27):2587-2599, 2010

7 Molina J-M et al. On-demand preexposure prophylaxis in man at high risk for HIV-1 infection. NEJM early online publication, DOI: 10.1056/NEJMoa1506273

8 McCormack $\mathrm{S}$ et al. Pre-exposure prophylaxis to prevent the acquisition of HIV-1 infection (PROUD): effectiveness results from the pilot phase of a pragmatic open-label randomised trial. The Lancet, early online publication. DOI: http://dx.doi.org/10.1016/S0140-6736(15)00056-2. 2015.

9 Rodger AJ et al. http://programme.aids2018.org/Abstract/Abstract/13470

10 Bedford Programme www.sementesting.org; accessed 24 ${ }^{\text {th }}$ April 2018

11 Kushnir V and Lewis W. HIV/AIDS and Infertility: Emerging Problems in the Era of Highly Active Antiretrovirals. Fertil Steril. 2011 Sep; 96(3): 546-553. Published online 2011 Jun 30. doi: 10.1016/j. fertnstert.2011.05.094

12 s54 Human Fertilisation and Embryology Act 2008;

https://www.legislation.gov.uk/ukpga/2008/22/contents; accessed 14th April 2018

13 s42-44 Human Fertilisation and Embryology Act 2008; 
14 Höfner C, Schadler C and Richter R (2011). When men become fathers: Men's identity at the transition to parenthood. Journal of Comparative Family Studies, 42(5), 669-686.

15 Jaspal R \& Dhairyawan R (2018). Sexual health, HIV \& mental health in BAME communities in the UK. In R. Raghavan (Ed. ), Mental Health, Ethnicity and Cultural Diversity: Narratives for Transformative Services. Bingley: Emerald Publishing Limited.

16 Jaspal R (2018). Enhancing Sexual Health, Self-Identity \& Wellbeing among Men Who Have Sex With Men: A Guide for Practitioners. London: Jessica Kingsley Publishers.

17 BHIVA Standards 2018 http://www.bhiva.org/documents/Standards-of-care/2018/BHIVAStandards-of-Care-2018.pdf; accessed $7^{\text {th }}$ August 2018 